\title{
An Examination of Competitive Anxiety and Self-Confidence among College Varsity Athletes 大學代表隊選手之競賽焦虑與自信的檢驗研究
}

\author{
Howard Z. ZENG ${ }^{1}$ Raymond W. LEUNG ${ }^{1}$ Wenhao LIU $^{2}$ \\ ${ }^{1}$ The City University of New York, Brooklyn College, \\ Brooklyn, New York, USA \\ ${ }^{2}$ Slippery Rock University, Slippery Rock, Pennsylvania, USA
}

\author{
曾振豪 ${ }^{1}$ 梁偉文 ${ }^{1} \quad$ 劉文浩 $^{2}$ \\ 美國紐約市立大學布魯克林學院 \\ 2賓夕凡尼亞州斯立彼里拉克大學
}

\begin{abstract}
The purpose of this study was to examine the relationships between competitive anxiety and self-confidence among collegiate varsity athletes. Participants were 96 athletes from a university in the United States, and their sport affiliations included baseball, volleyball, softball, track and field, and gymnastics. The following four questionnaires were administered to the participants: Competitive State Anxiety Inventroy-2, State Sport-Confidence Inventory, Sport Competition Anxiety Test for Adults, and Trait Sport-Confidence Inventory. Data were analyzed by Pearson product-moment correlations. Results showed that athletes who possessed a low level of competitive trait anxiety on a regular practice day tended to have low levels of cognitive state anxiety and somatic state anxiety, as well as high levels of state self-confidence and state sportconfidence on a competition day. In addition, athletes who possessed a high level of trait sport-confidence on a regular practice day tended to have low levels of cognitive state anxiety and somatic state anxiety, and high levels of state selfconfidence and state sport-confidence on a competition day. The present investigation also found that cognitive state anxiety and somatic state anxiety were the predictors to estimate athletes' self-confidence and performance.
\end{abstract}

\section{摘要}

本文旨在檢驗大學生運動員的競賽焦慮與自信之間的相關聯繫, 研究對象為美國一所大學的九十六名大學生運動員, 他們 所在的運動隊包括壘球、排球、棒球、田徑和體操。四個調查問卷(其中兩個用於測量競賽焦慮，兩個用來調查運動員的自信心) 被用來收集數據。並採用佩爾森運動相關係數檢驗法對數據進行了分析。結果表明:在正常訓練日裡具有低水平特質性競賽焦慮 的運動員傾向於在競賽之日具有低水平的認知性焦慮和軀體性焦慮, 但具有較高水平的狀態運動性自信心。而在正常的訓練日具 有高水平的特質性運動自信心的運動員傾向於在競賽之日具有低水平的認知性焦慮與軀體性焦慮。本研究也證實了認知性焦慮與 軀體性焦慮為兩項預測運動員自信心與競技表現的有效指示。

\section{Introduction}

In the arena of sport, psychologists and coaches have paid much attention to explore and interpret the theories, features, and relationships among competitive anxiety, sport confidence, and athletes' performance (Martens, Burton, Vealey, Bump, \& Smith, 1990; Robazza \& Bortoli, 2007; Vealey, 1986; Voight, Callaghan, \& Ryska, 2000; Williams, 1998). Competitive anxiety is composed of state anxiety 
and trait anxiety (Cox, 1998; Martens, et al., 1990; Weinberg \& Gould, 1995). Cox (1998) stated that, "state anxiety is an immediate emotional state that is characterized by apprehensive, fear, tension, and an increase in physiological arousal." (p. 93).

While trait anxiety is a tendency to perceive certain environmental situations as threatening, and to respond to these situations with an increased state anxiety. Furthermore, researchers have extended and developed the one-dimensional of anxiety theory into the multidimensional theory of anxiety (Endler, 1978; Fisher \& Zwart, 1982; Gould, Horn, \& Spreeman 1983). Cox (1998) pointed out that, "multidimensional anxiety theory has resulted in a number of inventories that approach anxiety from a multidimensional as opposed to unidimentional perspective." (p. 97). A typical example was the development of the competitive state anxiety inventory-2 (CSAI-2), which is a well-known and frequently-used instrument for measuring competitive anxiety in sport.

Related to specific situations in the arena of competitive sport, Martens, et al. (1990) stated that the CSAI-2 assessed sport-specific cognitive and somatic anxiety, called cognitive state anxiety and somatic state anxiety respectively. Cognitive state anxiety was defined as the mental component of state anxiety caused by fear of negative social evaluation, fear of failure, and loss of self-esteem. Somatic state anxiety was defined as the physical component of anxiety and reflected the perception of physiological responses as increased heart rate, respiration, and muscular tension (Martens, et al., 1990).

Regarding the relationships among competitive anxiety, self-confidence, and performance of athletes, Martens, et al. (1990) declared that somatic state anxiety and state self-confidence would be positively related to athletes' performance while cognitive state anxiety would be negatively related to athletes' performance. Recently, Robazza and Bortoli (2007) found that rugby players experienced a moderate frequency of anger symptoms. In addition, cognitive anxiety was found to be a major predictor of anger while self-confidence was a main predictor for anger controlling (Robazza \& Bortoli, 2007).

On the other hand, self-confidence is the "feeling or belief in one's own abilities" while sport-confidence is the "perception of confidence in a sport-related achievement situation." (Cox, 1998; p. 271). Literatures on sport self- confidence and performance of athletes suggested that successful athletes are self-confident persons and their confidence is developed from their athletic journey, which is the evidence of their effective thinking and unique experiences in the sport they have been successful (Feltz, 1988; Jones \& Cale, 1989; Krane \& Williams, 1987; Robazza \& Bortoli, 2007; Zinsser, Bunker, \& Williams, 1998).

Vealey (1986) developed a sport confidence model which provided a unique manner to conceptualize the accomplishments on studying motivation and self-confidence in sport. She defined sport confidence as the feeling or belief in one's ability to be successful in the sport one is engaging. Vealey (1986) stated that the level of athletes' sport-confidence could be used as a predictor of their competitive performance.

Vealey's model of sport confidence is composed of trait sport-confidence and state sport-confidence. The trait sport-confidence is related to an athlete's personality trait and is particularly competitive-oriented. The state sportconfidence is related to an athlete's physiological symptom that is reflected from the situation specific to the sport he/she is engaging (Vealey, 1986).

Cox (1998) stated that the Vealey's model of sport confidence is useful to explore the relationship between athletes' situation-specific sport confidence and their competitive performance. In order to protect against potentially negative thoughts and feelings experienced in competitive settings, elite athletes need to develop specific sport self-confidence as an essential trait (Hanton, Mellalieu, \& Hall, 2004).

To briefly summarize, researchers in competitive anxiety and self-confidence have accomplished abundantly and the findings have been well-documented. The phenomena of competitive anxiety and self-confidence are the two vital factors that related to athletes' performance in the arena of competition sport (Bandura, 1990; Feltz, 1988; Hanton, Mellalieu, \& Hall, 2004; Jones \& Cale, 1989; Voight, Callaghan, \& Ryska, 2000). Many previous studies, however, have dealt with these two factors separately and there were limited data-based studies available investigating their relation. Moreover, participants involved in previous research studies were either elite or youth athletes, and the athletes at the National Collegiate Athletics Association (NCAA) Division III level have 
seldom been investigated. The purpose of this study was therefore to examine the relationships between competitive anxiety and self-confidence in athletes at the NCAA Division III level.

\section{Methods}

\section{Participants}

Ninety-six varsity athletes (69 males and 27 females) from a NCAA Division III university in the east coast of the United States volunteered to participate in the study. The age of the participants ranged from 19 to 24 years $(\mathrm{M}=21.0 \pm 2.5$ years $)$, and their sport affiliations were baseball, volleyball, track and field, softball, and gymnastics. Participants completed four questionnaires: (a) Competitive State Anxiety Inventroy-2 (CSAI-2), (b) State Sport-Confidence Inventory, (c) Sport Competition Anxiety Test for Adults, and (d) Trait Sport-Confidence Inventory. The first two questionnaires ( $\mathrm{a}$ and $\mathrm{b}$ ) were administered immediately before scheduled competitions whereas the other two questionnaires ( $c$ and $d$ ) were completed on practice days which were scheduled one week after the administration of the first two questionnaires. These four questionnaires produced three anxiety variables (competitive trait anxiety, cognitive state anxiety, and somatic state anxiety) and three confidence variables (state self-confidence, trait sport-confidence, and state sportconfidence). Pearson product-moment correlation analyses were conducted among the six variables. Participants were excluded from the study if they failed to complete the entire questionnaire. Informed consent was obtained from each participant prior to the beginning of this investigation that was approved by the Institutional Review Board.

\section{Measurement Instruments}

All psychological factors in the current study were measured by the following instruments: (a) Sport Competition Anxiety Test for Adults (SCAT-A) (Martens, Vealey, \& Burton, 1990); (b) Competitive State Anxiety Inventory-2 (CSAI-2) (Martens, et al., 1990); (c) The Trait Sport-Confidence Inventory (TSCI) (Vealey, 1986); and (d) The State Sport-Confidence Inventory (SSCI) (Vealey, 1986). The reliability and validity of the instruments used have been previously defined by Martens, et al. (1990), Martens, Vealey, and Burton (1990), and Vealey (1986).

\section{Instrument I: SCAT-A}

The Sport Competition Anxiety Test for Adults (SCAT-A) (Martens, Vealey, \& Burton, 1990) was used to determine the cognitive state anxiety, somatic state anxiety, and state self-confidence levels of participants. The SCATA consisted of 15 items, and each item had a 3-point ordinal response scale. Items 1-5, 7-10, and 12-15 scored from 1 to 3 ( 1 = hardly ever, $2=$ sometimes, and 3 $=$ often). Scoring for items 6 and 11 used a reversed manner (i.e. $1=$ often, $2=$ sometimes, and $3=$ hardly ever). The lowest possible score was 10 (i.e. the lowest level of the competitive trait anxiety) and the highest possible score was 30 (i.e. the highest level of the competitive trait anxiety).

\section{Instrument II: CSAI-2}

The Competitive State Anxiety Inventory-2 (CSAI2) (Martens, et al., 1990) was used to determine the cognitive state anxiety, somatic state anxiety, and state self-confidence levels of participants. The CSAI-2 consisted of 27 items, and the response to each item was scored on a Likert scale, ranging from 1 (not at all) to 4 (very much so). The CSAI-2 consisted of three subscales used to measure cognitive state anxiety, somatic state anxiety, and state self-confidence with scores ranging from a low of 9 to a high of 36 (Martens, et al. 1990). The higher the score, the higher the state anxiety or the state self-confidence (Martens, et al. 1990). A total score for the scale was not needed. The CSAI-2 was to be administered as close to competition as possible with a maximum of $1 \mathrm{hr}$ before competition (Martens, et al., 1990).

\section{Instruments III and IV: TSCI and SSCI}

The Trait Sport-Confidence Inventory (TSCI) (Vealey, 1986) and the State Sport-Confidence Inventory (SSCI) (Vealey, 1986) were used to determine the trait sportconfidence and the state sport-confidence levels of the participants. The TSCI consisted of 13 items that reflected various aspects of sport performances. Item examples included, "compare your confidence in your ability to execute successful strategy to the most confident athlete you know." and "compare your confidence in your ability to be successful to the most confident athlete you know." (Vealey, 1986). Response to each item was on a 9-point Likert scale, ranging from low to high. The score was computed by summing all responses (Vealey, 1986). The SSCI also had 13 items with each item rated on a 
9-point Likert scale (Vealey, 1986). Prior to competitions, participants were asked to indicate their personality state. The SSCI-A score was computed by summing all responses.

\section{Procedures}

All participants were tested in a team setting. The procedure included two separate phases administered on separate days. During the first phase, the CSAI-2 (Martens, et al., 1990) and SSCI (Vealey, 1986) were administered on the day of a scheduled competition and as close as possible prior to a competition. The second phase, the SCAT-A (Martens, Vealey, \& Burton, 1990) and the TSCI (Vealey, 1986) were administered on a practice day that was within five days after the first phase of testing. Martens, et al. (1990) and Vealey (1986) indicated that, in order to obtain an ideal testing result, both CSAI2 and SSCI should be administered before SCAT and TSCI. Before testing, each participant was given the following instructions: 1) answer each question as it applies to yourself, 2) give only one answer to each question, 3) answer all questions, and 4) after finished all questionnaires, return them back to the administrator.

\section{Statistical Analysis}

Data from the four questionnaires were analyzed and descriptive statistics were computed for the following traits: competitive trait anxiety, cognitive state anxiety, somatic state anxiety, state self-confidence, trait sportconfidence, and state sport-confidence variables. The correlations of these variables were assessed using Pearson product-moment correlations. The correlation coefficients were compared to a Table $r$ value of $+.267(\mathrm{df}=94)$ and tested at the .01 alpha level.

\section{Results}

The descriptive statistics for the six variables are presented in Table 1.

Table 1. Descriptive Statistics for State and Trait Anxiety, and State and Trait SportConfidence $(\mathbf{N}=96)$.

\begin{tabular}{lcc}
\hline Variables & $\mathrm{M}$ & $\mathrm{SD}$ \\
\hline CSA & 19.85 & 4.35 \\
SSA & 17.09 & 4.31 \\
SSC & 26.25 & 4.57 \\
SC-State & 87.86 & 15.03 \\
CTA & 19.24 & 4.16 \\
TSC & 90.22 & 13.23 \\
\hline
\end{tabular}

Note: CSA = Cognitive State Anxiety, SSA = Somatic State Anxiety, SSC = State Self-Confidence, SCState $=$ State Sport-Confidence, $\mathrm{CTA}=$ Competitive Trait Anxiety, and TSC = Trait Sport-Confidence.

The correlations of the anxiety and self-confidence scores are displayed in Table 2. The top five positive correlations were (1) state sport-confidence vs. trait sportconfidence $(\mathrm{r}=.663, \mathrm{p}<.01)$; (2) somatic state anxiety vs. competitive trait anxiety $(\mathrm{r}=.643, \mathrm{p}<.01)$; (3) state self-confidence vs. state sport-confidence $(\mathrm{r}=.568, \mathrm{p}<$ $.01)$; (4) cognitive state anxiety vs. somatic state anxiety $(\mathrm{r}=.511, \mathrm{p}<.01)$; and (5) state self-confidence vs. trait sport-confidence $(\mathrm{r}=.451, \mathrm{p}<.01)$.

In contrast, the top five negative correlation coefficients were (1) somatic state anxiety vs. state selfconfidence $(\mathrm{r}=-.476, \mathrm{p}<.01)$; (2) somatic state anxiety vs. state sport-confidence $(r=-.467, \mathrm{p}<.01)$; (3) competitive trait anxiety vs. state sport-confidence ( $\mathrm{r}$ $=-.466, \mathrm{p}<.01) ;(4)$ competitive trait anxiety vs. state self-confidence $(\mathrm{r}=-.457, \mathrm{p}<.01)$; and $(5)$ somatic state anxiety vs. trait sport-confidence $(\mathrm{r}=-.434, \mathrm{p}<.01)$. Based on the raw data, two scattergrams were utilized to present the relationship between sport anxiety and selfconfidence. The relationship between cognitive state anxiety 
and state sport-confidence is presented in Figure 1. The relationship between somatic state anxiety and trait sportconfidence is presented in Figure 2.

Table 2. Correlation Coefficients for Competitive State and Trait Anxiety and State and Trait Sport-Confidence of College Varsity Athletes $(\mathbf{N}=96)$.

\begin{tabular}{|c|c|c|c|c|c|c|}
\hline & CSA & SSA & SSC & SC-State & CTA & TSC \\
\hline CSA & -- & & & & & \\
\hline SSA & $.511^{*}$ & - & & & & \\
\hline SSC & $-.457^{*}$ & $-.476^{*}$ & -- & & & \\
\hline SC-State & $-.466^{*}$ & $-.467^{*}$ & $.568^{*}$ & -- & & \\
\hline CTA & $.407^{*}$ & $.643^{*}$ & $-.427^{*}$ & $-.376^{*}$ & -- & \\
\hline TSC & $-.281^{*}$ & $-.434^{*}$ & $.451^{*}$ & $.663^{*}$ & $-.377^{*}$ & -- \\
\hline
\end{tabular}

$* \mathrm{p}<.01 . \mathrm{CSA}=$ Cognitive State Anxiety, SSA = Somatic State Anxiety, SSC = State Self-Confidence, SCState $=$ State Sport-Confidence, CTA $=$ Competitive Trait Anxiety, and TSC = Trait Sport-Confidence.

\section{Discussions}

The purpose of the present study was to examine the relationships among six psychological variables of anxiety and self-confidence in varsity athletes at the NCAA Division III level. The findings of this investigation were summarized as follows. Athletes who had a higher level of cognitive state anxiety indicated a higher level of somatic state anxiety, and these athletes also expressed a lower level of state self-confidence. Athletes who possessed a higher level of competitive trait anxiety also expressed a lower level of state sportconfidence and trait sport-confidence. Athletes who had a higher level of competitive trait anxiety on a practice day also possessed higher levels of cognitive state anxiety and somatic state anxiety on a competition day. Athletes who indicated a higher level of trait sport-confidence on a practice day also expressed higher levels of state sportconfidence and state self-confidence on a competition day.

The above results were consistent with the findings of previous studies in regard to the relationship of competitive anxiety and athletes' performance (Jones \& Cale, 1989; Martens, et al., 1990; Robazza \& Bortoli, 2007; Voight, Callaghan, \& Ryska, 2000), in which cognitive state anxiety was described as an extremely influential construct. Similarly, in the present investigation, cognitive state anxiety was negatively associated with the level of state self-confidence and state sport-confidence (see Table 2).

It might be assumed that an athlete possessing a lower level of cognitive state anxiety would show a higher level of state self-confidence. Interestingly, the current study found that somatic state anxiety was a stronger influential construct associated with the level of state self-confidence as compared to the cognitive state anxiety level. Moreover, this study also found that the competitive trait anxiety was associated with state selfconfidence, trait sport-confidence, and state sport-confidence in the same pattern as associated with cognitive state anxiety and somatic state anxiety (see Figures 1 and 2).

In summary, the following four points appeared to be meaningful predictors for athletes' performance: (a) using somatic state anxiety to predict state self-confidence; (b) using somatic state anxiety to predict state sportconfidence; (c) using cognitive state anxiety to predict state sport-confidence; and (d) using cognitive state anxiety to predict state self-confidence.

The findings of the current study also supported the findings by Martens, et al. (1990) and Vealey (1986). For instance, Martens, et al. (1990) indicated that cognitive and somatic state anxieties were strongly associated with competitive trait anxiety that could be tested by the Sport Competition Anxiety Test for Adults (SCAT-A). Martens, Vealey, and Burton (1990) also indicated that SCAT-A should be correlated higher with the somatic anxiety than that with the cognitive anxiety or state self-confidence, because of the nature of the SCAT-A items. By testing the essential functions of her sport-confidence model, Vealey (1986) found a significant relationship between the state self-confidence and the state sport-confidence as measured by the State Sport-Confidence Inventory. The findings of the current study further confirmed their hypotheses and theories. 
In conclusion, the relationships between competitive anxiety and self-confidence for the collegiate varsity athletes are as follow. Athletes who possess a low level of competitive trait anxiety on a regular practice day tend to have low levels of cognitive state anxiety and somatic state anxiety, as well as high levels of state selfconfidence, state sport-confidence on a competition day. Athletes who possess a high level of trait sport-confidence on a regular practice day tend to have low levels of cognitive state anxiety and somatic state anxiety, as well as high levels of state self-confidence and state sportconfidence on a competition day.

The findings of this investigation imply that cognitive state anxiety and somatic state anxiety are two crucial predicators for predicting athletes' self-confidence and performance. Based on these two predicators, athletes

Figure 1. Relationship between Cognitive State Anxiety and State Sport-Confidence.

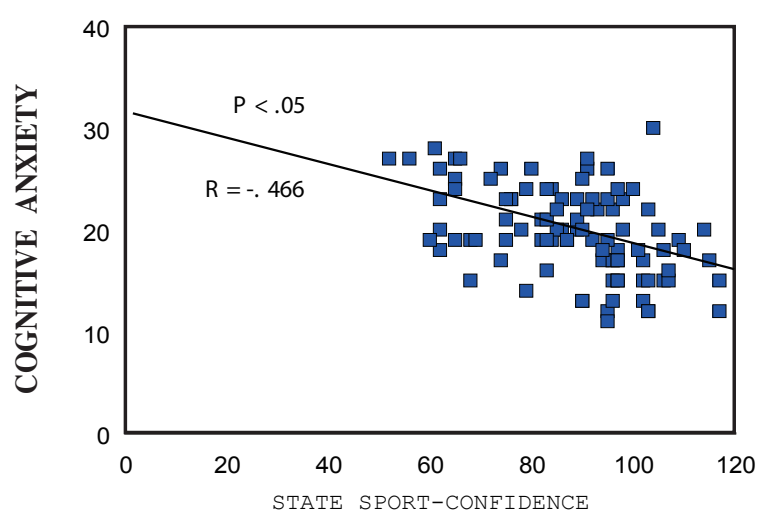

Figure 1. Relationship between Cognitive State Anxiety State Sport-Confidence. may be able to reduce their competitive anxiety level by participating in certain mental training exercises designed to reduce competitive anxiety prior to competitions. Moreover, the results of this investigation offer the following recommendations. First, coaches and athletes should possess essential competitive anxiety and selfconfidence knowledge in order to apply certain anxiety relaxation techniques. Second, athletes should be provided with mental training to reduce their competitive anxiety and increase their self-confidence by using anxiety relaxation techniques during practice sessions. Third, coaches could use anxiety and self-confidence testing results in a positive way; for instance, interventions for decreasing any anxiety might result in a decrease in the other two anxiety variables and an increase in the other confidence variables. Examinations of intervention strategies appear to be the direction for further investigation.

Figure 2. Relationship between Somatic State Anxiety and Trait Sport-Confidence.

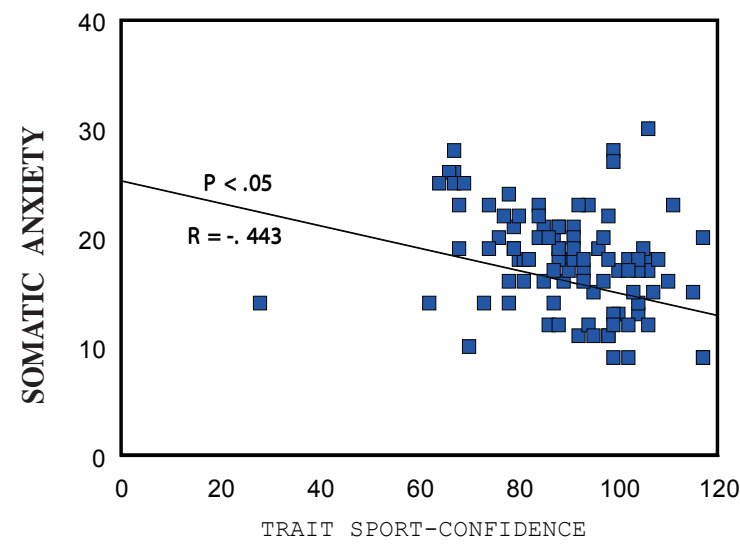

Figure 2. Relationship between Somatic State Anxiety and Trait Sport-Confidence. 


\section{References}

Bandura, A. (1990). Perceived self-efficacy in the exercise of personal agency. Journal of Applied Sport Psychology, 2, 128-163.

Feltz, D. L., (1988). Self-confidence and sports performance. Exercise and Sport Sciences Reviews, 16, 423-457.

Feltz, D. L., \& Mugno, D. A. (1983). A replication of the path analysis of the causal elements in Bandura's theory of self-efficacy and the influence of autonomic perception. Journal of Sport Psychology, 5, 263-277.

Fisher, A. C., \& Zwart, E. F. (1982). Psychological analysis of athletes' anxiety responses. Journal of Sport Psychology, 4, 139-158.

Gould, D., Horn, T., \& Spreeman, J. (1983). Sources of stress in junior elite wrestlers. Journal of Sport Psychology, 5, 159-171.

Hanton, S., Mellalieu, S. D., \& Hall, R. (2004). Selfconfidence and anxiety interpretation: A qualitative investigation. Psychology of Sport and Exercise, 5, 477-495.

Jones, J., \& Cale, A. (1989). Precompetition temporal patterning of anxiety and self-confidence in males and females. Journal of Sport Behavior, 12, 183-195.

Krane, V., \& Williams, J. (1987). Performance and somatic anxiety, cognitive anxiety, and confidence changes prior to competition. Journal of Sport Behavior, 10, 47-56.

Martens, R., Burton, D., Vealey, R. S., Bump, L. A., \& Smith, D. E. (1990). Development and validation of the Competitive State Anxiety Inventory-2. In R. Martens, R. Vealey, \& D. Burton (Eds.), Competitive anxiety in sport (pp. 117-213). Champaign, IL: Human Kinetics.

Martens, R., Vealey, R. S., \& Burton, D. (Eds.). (1990). Competitive anxiety in sport. Champaign, IL: Human Kinetics.
Rainey, D. W., \& Cunningham, H. (1988). Competitive trait anxiety in male and female college athletes. Research Quarterly for Exercise and Sport, 59, 244247.

Robazza, C., \& Bortoli, L. (2007). Perceived impact of anger and anxiety on sporting performance in rugby players. Psychology of Sport and Exercise, 8, 875896.

Vealey, R. (1986). Conceptualization of sport-confidence and competitive orientation: Preliminary investigation and instrument development. Journal of Sport Psychology, 8, 221-246.

Voight, M. R., Callaghan, J. L., \& Ryska, T. A. (2000). Relationship Between goal orientations, self-confidence and multidimensional trait anxiety among MexicanAmerican female youth athletes. Journal of sport Behavior, 23, 271-288.

Weinberg, R., Gould, D., \& Jackson, A. (1979). Expectations and performance: An empirical test of Bandura's self-efficacy theory. Journal of Sport Psychology, 1, 320-331.

Weinberg, R. S., \& Gould, D. (1995). Foundations of sport and exercise psychology. Champaign, IL: Human Kinetics.

Williams, J. M. (1998). Applied Sport Psychology: Personal growth to peak performance ( $3^{\text {rd }}$ ed.). Mountain View, CA: Mayfield.

Zinsser, N., Bunker, L., \& Williams, J. M. (1998). Cognitive techniques for building confidence and enhancing performance. In Williams, J. M. (1998). Applied Sport Psychology: Personal growth to peak performance $\left(3^{\text {rd }}\right.$ ed.). Mountain View, CA: Mayfield.

\section{Corresponding Address:}

Howard Zeng or Raymond Leung

Department of Physical Education and

Exercise Science

Brooklyn College, The City University of New York 2900 Bedford Avenue, Brooklyn,

New York, 11210, USA

Email: rleung@brooklyn.cuny.edu 